\title{
Developing Methane Isotopologues as Interplanetary Biosignatures
}

\author{
Edward D. Young
}

UCLA

Email: eyoung@epss.ucla.edu

Tel: 3102674930

William D. Leavitt

Dartmouth College

Email: william.d.leavitt@dartmouth.edu

Tel: 6036462978 


\begin{abstract}
The rare isotopologues of methane gas have great potential as a widely applicable biosignature throughout the Solar System. They are also superb tracers of abiotic chemistry. A thorough understanding of these species will inform future missions to Mars and the icy moons as to the potential benefits of including in-situ measurements of $\Delta^{12} \mathrm{CH}_{2} \mathrm{D}_{2}$ and $\Delta^{13} \mathrm{CH}_{3} \mathrm{D}$. The value of this potential biosignature relies critically on assessments of its success rate. If the associated confidence level as a biosignature is high, then developing methods to make these measurements on future missions would be high-priority. If the confidence is low or ambiguous, then such measurements would be considered less of a priority. Developing this new tool is therefore a moderate risk but high potential payoff proposition.
\end{abstract}

\title{
1 Introduction
}

Methane $\left(\mathrm{CH}_{4}\right)$ has great potential as a tracer of geochemical and atmospheric chemical processes in the solar system, in part because its potential biogenicity offers the attractive prospect of a biosignature (Yung et al., 2018). The power of methane as a tracer stems not merely from its presence or absence, although this is important, but also because it comprises a large number of isotopologues (isotopic varieties); the presence of two elements with two relatively abundant stable isotopes each in a molecule composed of 5 atoms results in a large information content. The origin of methane is an important issue for a number of solar system bodies, including Mars, Titan, Enceladus, and Pluto. The in-situ discovery of $\mathrm{CH}_{4}$ gas on Mars by Curiosity (Webster et al., 2015) was described as a "eureka moment" in planetary exploration (Yung et al., 2018). Similarly, detection of $\mathrm{CH}_{4}$ spewing forth from Saturn's moon Enceladus by the Cassini spacecraft (Waite et al., 2017) has focused attention on the possible origins of methane on icy ocean worlds.

The excitement surrounding the detection of $\mathrm{CH}_{4}$ on Mars is certainly in part because it might be microbial in origin. But the significance of the presence of methane goes well beyond its possible biogenicity. The contrast between the highly oxidized surface environments of Mars today and the presence of a tracer of reduced environments is a clue to the geochemistry of the planet past and present. A continuous source of methane is required to balance its atmospheric residence time of $\sim 300$ years as a result of rapid oxidation in the atmosphere triggered by photochemistry (Atreya et al., 2007; Lefèvre, 2019). Evidence for a seasonality to the effusion of $\mathrm{CH}_{4}$ has been taken as evidence for temporary storage in soils,

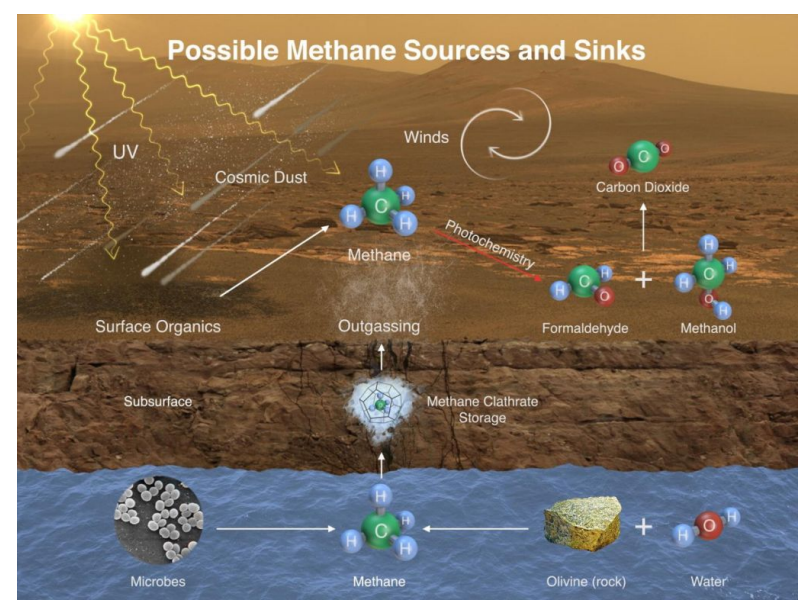

Figure 1: Possible sources and sinks of methane on Mars. Image credit: NASA/JPLCaltech/ SAM-GSFC/University of Michigan. offering some constraints on the sources, although the seasonality has been questioned recently (Gillen et al., 2020). Identifying the 
source of methane effusing from the surface is among the most pressing questions pertaining to the geochemistry of Mars.

The origin of methane in Enceladus is not known with certainty. It may be inherited from the accretion stage or the result of active serpentinization at the base of an internal ocean (Mousis et al., 2009; Bouquet et al., 2015). Extant molecular hydrogen in a setting where water-rock reactions are thought to occur favors serpentinization; serpentinization generates $\mathrm{H}_{2}$ gas that can lead to methane formation, either abiogenic or biogenic. The tantalizing possibility for microbial methanogenesis remains. Serpentinization at sufficiently low temperatures $\left(<\sim 100^{\circ} \mathrm{C}\right)$ can sustain chemolithotrophic life, and studies have explored the likelihood for conditions appropriate for methanogenic archaea to survive within Enceladus (Taubner et al., 2018).

Our understanding of the sources of methane in various planetary bodies has been stymied by the lack of unambiguous signatures of the provenance of the $\mathrm{CH}_{4}$ molecules (e.g., intraspecies tracers). This problem is exacerbated in extraterrestrial settings because our access to the geochemical context for the methane is limited by the nature of remote spacecraft observations. While the bulk carbon and hydrogen isotope ratios of methane gas, ${ }^{13} \mathrm{C} /{ }^{12} \mathrm{C}$ and $\mathrm{D} / \mathrm{H}$, have proven to be useful, if imperfect, tracers of the origin of methane in terrestrial environments (Schoell, 1980), they are of limited use for extraterrestrial applications where the source material is unknown. Bulk isotope ratios depend on both the sources of carbon and hydrogen that produce the methane and the processes by which the molecules form. However, in the settings of other worlds, with no a priori knowledge of the carbon and hydrogen budgets, deciphering the meaning of ${ }^{13} \mathrm{C} /{ }^{12} \mathrm{C}$ and $\mathrm{D} / \mathrm{H}$ ratios can be difficult. While extremely high $\mathrm{D} / \mathrm{H}$ ratios due to atmospheric escape are examples of unambiguous bulk isotope tracers, the more subtle variations conveyed to $\mathrm{CH}_{4}$ molecules depend on the $\mathrm{D} / \mathrm{H}$ ratios of the source hydrogen, which is generally unknown beyond Earth. For example, on Earth, methane formed in boreal lake settings tends to have low $\mathrm{D} / \mathrm{H}$ because of the low $\mathrm{D} / \mathrm{H}$ of the source water at high latitude. This is not a signature of the formation pathway, and methane formed by the same basic microbial methanogenesis process will have different $\mathrm{D} / \mathrm{H}$ ratios depending on latitude. In the case of carbon, low ${ }^{13} \mathrm{C} /{ }^{12} \mathrm{C}$ values are taken as signs of biotic carbon sources on Earth, but our knowledge of the meaning of ${ }^{13} \mathrm{C} /{ }^{12} \mathrm{C}$ values on Mars will remain limited for some time (e.g., Van Zuilen, 2008), not to mention the uncertainties surrounding those on Titan and Enceladus.

\section{Isotopologues as Tracers of Methane Provenance}

Multiply substituted isotopologes (isotopic variants) of gas molecules, often referred to as the isotopically "clumped" species, are well suited for determining the formation mechanism of a gas on another world where our understanding of the meaning of bulk isotope ratios is limited. These clumped species free us from the hindrance of needing to know the significance of bulk isotope ratios. This is because it is the abundances of these doubly-substituted species relative to their random abundances that are the clues to the origins of the gas, irrespective of the bulk isotope ratios themselves.

The term "isotopologue" refers to specific isotopic versions of the molecule of interest, and includes all isomeric variants. For example, the ${ }^{12} \mathrm{CH}_{3} \mathrm{D}$ isotopolouge here refers to 
the ${ }^{12} \mathrm{CH}_{3} \mathrm{D}+{ }^{12} \mathrm{CH}_{2} \mathrm{DH}+{ }^{12} \mathrm{CHDH}_{2}+{ }^{12} \mathrm{CDH}_{3}$ permutations of the D-substituted isotopic species of $\mathrm{CH}_{4}$ collectively. Three groups have thus far investigated rare isotopologues of methane in natural samples. Two groups have investigated the relative abundances of ${ }^{13} \mathrm{CH}_{3} \mathrm{D}$ in terrestrial settings as a tracer of the temperature of formation of methane and/or a tracer of reaction mechanism (e.g., Ono et al., 2014; Stolper et al., 2014; Wang et al., 2015). At UCLA we have focused on using the combination of ${ }^{13} \mathrm{CH}_{3} \mathrm{D}$ and ${ }^{12} \mathrm{CH}_{2} \mathrm{D}_{2}$ to disambiguate the multiple sources of methane gases using a process-oriented approach (Young et al., 2016, 2017; Haghnegahdar et al., 2017; Giunta et al., 2019; Ash et al., 2019; Young, 2019). The likelihood for acquiring measurements of the relative abundances of ${ }^{13} \mathrm{CH}_{3} \mathrm{D}$ and ${ }^{12} \mathrm{CH}_{2} \mathrm{D}_{2}$ by remote spacecraft in extraterrestrial settings has been enhanced by the development of a spectroscopic method for measuring both mass-18 methane species (Gonzalez et al., 2019), although large aliquotes of gas are currently needed.

We submit that an important goal should be to mitigate (if not eliminate) the uncertainties surrounding the use of bulk ${ }^{13} \mathrm{C} /{ }^{12} \mathrm{C}\left(\delta^{13} \mathrm{C}\right)$ and $\mathrm{D} / \mathrm{H}(\delta \mathrm{D})$ ratios alone for tracing the origin of methane gases, with the ultimate goal of developing isotopologue abundances in methane as a widely applicable biosignature. As a result of the last five years of study, we have collected sufficient data both in the laboratory and in the field to allow us to define fields on plots of $\Delta^{12} \mathrm{CH}_{2} \mathrm{D}_{2}$ vs. $\Delta^{13} \mathrm{CH}_{3} \mathrm{D}$ that distinguish the processes of methane formation. The $\Delta^{13} \mathrm{CH}_{3} \mathrm{D}$ and $\Delta^{12} \mathrm{CH}_{2} \mathrm{D}_{2}$ parameters are the \%o deviations from the abundances of these isotopologues if prescribed by random combinations of the carbon and hydrogen isotopes (the stochastic reference frame). As an illustration of the distinction between $\Delta^{13} \mathrm{CH}_{3} \mathrm{D}$ and $\Delta^{12} \mathrm{CH}_{2} \mathrm{D}_{2}$ values and bulk isotope ratios, consider that on the left-hand panel of Figure 2 the black solid curve represents $\Delta^{13} \mathrm{CH}_{3} \mathrm{D}$ and $\Delta^{12} \mathrm{CH}_{2} \mathrm{D}_{2}$ values at thermodynamic equilibrium as a function of temperature. The curve applies for all bulk isotope ratios; the values are the same for a gas at equilibrium regardless of whether the bulk $\delta \mathrm{D}$ is $-300 \%$ or +300 $\% o$ (relative to some reference like VSMOW), and so they would be unchanged regardless of which planet or icy moon hosts the methane.

Figure 2 shows $\sim 170$ analyses of methane samples from the field together with products of various experiments, including high-temperature synthesis experiments and axenic cultures. Fields are shown for gases of microbial origin, high-T formation (thermogenic gases), and abiotic formation (Fischer-Tropsch-type reactions, FTT, including the Sabatier reaction, and gases from the Kidd Creek mine, KC). The black equilibrium curve is labelled with temperatures of formation or equilibration. Grey symbols are for various localities not central to the arguments made here. Based on the clumping diagram in the left panel, the three endmember processes are well distinguished. On the bulk isotope diagram on the right, however, there is considerable overlap between thermogenic (derived from organic matter at high temperatures) and microbial gases (we will refer to the latter as microbialgenic to contrast with thermogenic). Both sources of biotic methane derive from biologically derived material, and thus tend to have low $\delta^{13} \mathrm{C}$ values, but they represent distinct processes and environmental histories (thermal breakdown vs. microbial). The data shown here happen to include a number of samples of microbialgenic gas from high-latitude wetlands, explaining the low $\delta$ D values compared with many of the thermogenic gases, giving the appearance of separation. However, separation in the panel on the right is due entirely to the $\delta \mathrm{D}$ of the source water rather than the processes of formation and is not universal.

The crucial difference between the panels on the left and right in Figure 2 is that the 

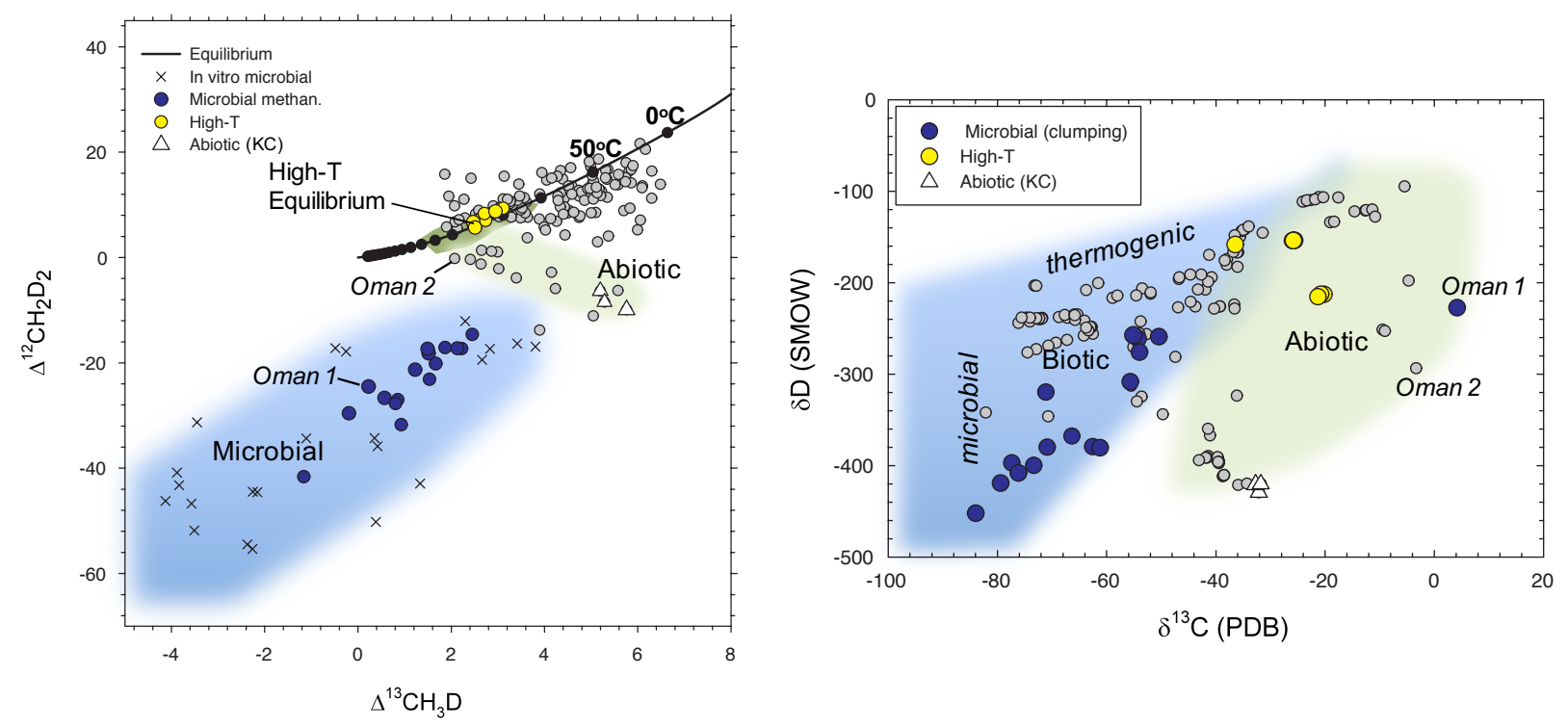

Figure 2: Comparison of data categorized by process in $\Delta^{12} \mathrm{CH}_{2} \mathrm{D}_{2}$ vs. $\Delta^{13} \mathrm{CH}_{3} \mathrm{D}$ space (left panel) to their positions in the bulk "Schoell" bulk isotope ratio plot (right panel). Fields on the left are based on the mass-18 isotopologue data from the UCLA laboratory, both published and unpublished. After Young (2019).

clumping diagram reflects process while the bulk isotope plot reflects both process and source. The latter poses a significant hurdle for applying bulk isotope ratios as a tracer of the origin of extraterrestrial methane, a hurdle that is to a large degree surmounted by application of $\Delta^{12} \mathrm{CH}_{2} \mathrm{D}_{2}$ vs. $\Delta^{13} \mathrm{CH}_{3} \mathrm{D}$ data as in the panel on the left. As an illustration, we show data for $\mathrm{CH}_{4}$ from the Samail Ophiolite, Oman (through collaboration with A. Templeton, U. of Colorado) in which the position for one datum (Oman 1) on the clumping diagram indicates a microbial source while the bulk isotopes suggest an abiotic source. If measured in isolation, with little geochemical context, the high $\delta^{13} \mathrm{C}$ value (right panel) would have no meaning and would be of little value. Conversely, using $\Delta^{12} \mathrm{CH}_{2} \mathrm{D}_{2}$ and $\Delta^{13} \mathrm{CH}_{3} \mathrm{D}$ values a microbial origin would be indicated. Lingering uncertainties about the effects of oxidation on $\Delta^{12} \mathrm{CH}_{2} \mathrm{D}_{2}$ values allows for an argument about whether the high $\delta^{13} \mathrm{C}$ is due to a high- ${ }^{13} \mathrm{C}$ source of carbon for microbial methanogenesis or if instead it is due to partial oxidation of abioitic methane. Uncertainties surrounding the veracity of $\Delta^{12} \mathrm{CH}_{2} \mathrm{D}_{2}$ as a biosignature allow the controversy to be fueled by ancillary geochemical arguments in a terrestrial environment, context that would not be available on other bodies. More work is required.

\section{Developing a Methane Biosignature for Other Worlds}

Methane produced by microbial methanogens is characterized by significant depletion, or "anti-clumping", in $\Delta^{12} \mathrm{CH}_{2} \mathrm{D}_{2}$ of 20 to $50 \%$ or more, relative to thermodynamic equi- 
librium (Young et al., 2017; Young, 2019). These $\Delta^{12} \mathrm{CH}_{2} \mathrm{D}_{2}$ depletions are accompanied by proportionately smaller deficits in $\Delta^{13} \mathrm{CH}_{3} \mathrm{D}$ (Figure 2). This deficit in $\Delta^{12} \mathrm{CH}_{2} \mathrm{D}_{2}$ in particular is a biosignature. We recently identified the source of this deficit. The study, a collaboration between the authors and their groups (Taenzer et al. 2020), showed through a series of experiments that the low ${ }^{12} \mathrm{CH}_{2} \mathrm{D}_{2}$ signature comes from the "combinatorial" effect, a phenomenon first identified in the laboratory at UCLA (Yeung et al., 2015; Yeung, 2016; Röckmann et al., 2016). This effect is an isotopologue manifestation of the inequality between the geometric and arithmetic means. Succinctly stated, the geometric mean is always equal to or less than the arithmetic mean. Methane molecules built from more than one source of hydrogen with distinct deuterium/protium isotope ratios have isotopologue abundances reflecting the geometric mean of these isotope ratios, but the original isotope ratios of the source atoms are no longer discernible in the mixture comprising the methane molecules. The original geometric mean is therefore unknown. An anomalously low concentration of ${ }^{12} \mathrm{CH}_{2} \mathrm{D}_{2}$ relative to the reference "stochastic" value results because the stochastic value is based on the arithmetic mean isotope ratio measured in our mass spectrometers. We now have a robust explanation for our earlier observations.

Although it is clearly relevant to microbially produced methane, until very recently (Taenzer et al., 2020), the combinatorial effect was not yet demonstrated in any experimental study. In order to evaluate the fidelity of this new biosignature, a rigorouos program of natural and laboratory-based experiments is warranted. An experimental program is necessary to constrain the mechanistic relationships between exogenous (environmental) and endogenous (mechanism specific) factors that produce clumped isotopic signatures in microbially produced or altered methane. In parallel, experiments examining the $\Delta^{12} \mathrm{CH}_{2} \mathrm{D}_{2}$ and $\Delta^{13} \mathrm{CH}_{3}$ D signatures of abitoic methane synthesis under a variety of conditions are crucial.

Other key unknowns surrounding the veracity of $\Delta^{12} \mathrm{CH}_{2} \mathrm{D}_{2}$ and $\Delta^{13} \mathrm{CH}_{3} \mathrm{D}$ as biosignatures require experimental attention. Axenic cultures, including the methylotrophic and hydrogenotrophic pathways, and samples of microbialgenic methane from boreal wetlands and a salt marsh from California exhibit the combinatorial effect associated with microbial methanogenesis. However, the relevance to all methane gases produced microbially has been questioned.

Aerobic methane oxidation could conceivably alter the $\Delta^{12} \mathrm{CH}_{2} \mathrm{D}_{2}$ and $\Delta^{13} \mathrm{CH}_{3} \mathrm{D}$ values of a gas and confound the use of these isotopologues as biosignatures. The crucial parameter in this regard is somewhat arcane; the deviation of the ${ }^{12} \mathrm{CH}_{2} \mathrm{D}_{2} / \mathrm{CH}_{4}$ fractionation factor, $\alpha_{\mathrm{CH}_{2} \mathrm{D}_{2}}$, from the rule of the geometric mean (RGM) which suggests that ideally $\alpha_{\mathrm{CH}_{2} \mathrm{D}_{2}}=$ $\left(\alpha_{\mathrm{CH}_{3} \mathrm{D}}\right)^{2}$. The paths taken in $\Delta^{12} \mathrm{CH}_{2} \mathrm{D}_{2}$ vs. $\Delta^{13} \mathrm{CH}_{3} \mathrm{D}$ space with oxidation depend on this deviation that is described using $\gamma=\alpha_{\mathrm{CH}_{2} \mathrm{D}_{2}} /\left(\alpha_{\mathrm{CH}_{3} \mathrm{D}}\right)^{2}$. Theory suggests that $\gamma<1$ is the rule for ${ }^{12} \mathrm{CH}_{2} \mathrm{D}_{2}$, in turn suggesting that oxidation of abiotic methane will not cause a false positive biosignature. However, we require experimental data on the effects of bacterial oxidation on methane gas to assess the likelihood that this process could either produce a spurious methane biosignature or erase a valid signature.

These are few of the types of studies that should lead to a quantitative assessment of what could prove to be a robust geochemical biosignature in planetary settings where the more usual bulk isotope ratios are of limited use. 


\section{References and Citations}

Ash, J., Egger, M., Treude, T., Kohl, I., Cragg, B., Parkes, R., Slomp, C., Sherwood Lollar, B., \& Young, E. 2019, Geochemical Perspectives Letters, 26

Atreya, S. K., Mahaffy, P. R., \& Wong, A.-S. 2007, Planetary and Space Science, 55, 358

Bouquet, A., Mousis, O., Waite, J. H., \& Picaud, S. 2015, Geophysical Research Letters, 42, 1334

Gillen, E., Rimmer, P. B., \& Catling, D. C. 2020, Icarus, 336, 113407

Giunta, T., Young, E. D., Warr, O., Kohl, I., Ash, J. L., Martini, A., Mundle, S. O., Rumble, D., Pérez-Rodríguez, I., Wasley, M., LaRowe, D. E., Gilbert, A., \& Sherwood Lollar, B. 2019, Geochimica et Cosmochimica Acta, 245, 327

Gonzalez, Y., Nelson, D. D., Shorter, J. H., McManu, B. J., Dyroff, C., Formolo, M., Wang, D. T., Western, C. M., \& Ono, S. 2019, Analytical Chemistry, 91, 14967

Haghnegahdar, M. A., Schauble, E. A., \& Young, E. D. 2017, Global Biogeochemical Cycles, 31,1387

Lefèvre, F. 2019, The Enigma of Methane on Mars, ed. B. Cavalazzi \& F. Westall, 253-266

Mousis, O., Lunine, J. I., \& Waite, J. H. 2009, in SF2A-2009: Proceedings of the Annual meeting of the French Society of Astronomy and Astrophysics, ed. M. Heydari-Malayeri, C. Reyl'E, \& R. Samadi, 241

Ono, S., Wang, D. T., Gruen, D. S., Sherwood Lollar, B., Zahniser, M. S., McManus, B. J., \& Nelson, D. D. 2014, Analytical Chemistry, 86, 6487

Röckmann, T., Popa, M. E., Krol, M. C., \& Hofmann, M. E. G. 2016, Scientific Reports, 6, 31947

Schoell, M. 1980, Geochimica et Cosmochimica Acta, 44, 649

Stolper, D. A., Lawson, M., Davis, C. L., Ferreira, A. A., Neto, E. V. S., Ellis, G. S., Lewan, M. D., Martini, A. M., Tang, Y., Schoell, M., Sessions, A. L., \& Eiler, J. M. 2014, Science, 344,1500

Taenzer, L., Labidi, J., Masterson, A. M., Feng, X., Rumble, D, I., Young, E. D., \& Leavitt, W. D. 2020, Geochimica et Cosmochimica Acta (in review)

Taubner, R.-S., Pappenreiter, P., Zwicker, J., Smrzka, D., Pruckner, C., Kolar, P., Bernacchi, S., Seifert, Arne H. andKrajete, A., Bach, W., Peckmann, J., Paulik, C., Firneis, M. G., Schleper, C., \& Rittman, S. K.-M. 2018, Nature Communications, 748, 11 pp.

Van Zuilen, M. 2008, Space Scienc Reviews, 135, 221 
Waite, J. H., Glein, C. R., Perryman, R. S., Teolis, B. D., Magee, B. A., Miller, G., Grimes, J., Perry, M. E., Miller, K. E., Bouquet, A., Lunine, J. I., Brockwell, T., \& Bolton, S. J. 2017, Science, 356, 155

Wang, D. T., Gruen, D. S., Lollar, B. S., Hinrichs, K.-U., Stewart, L. C., Holden, J. F., Hristov, A. N., Pohlman, J. W., Morrill, P. L., Konneke, M., Delwiche, K. B., Reeves, E. P., Sutcliffe, C. N., Ritter, D. J., Seewald, J. S., McIntosh, J. C., Hemond, H. F., Kubo, M. D., Cardace, D., Hoehler, T. M., \& Ono, S. 2015, Science, 348, 428

Webster, C. R., Mahaffy, P. R., Atreya, S. K., \& Flesch, G. 2015, in AGU Fall Meeting Abstracts, Vol. 2015, P43B-2110

Yeung, L. Y. 2016, Geochimica et Cosmochimica Acta, 172, 22

Yeung, L. Y., Ash, J. L., \& Young, E. D. 2015, Science, 348, 431

Young, E. 2019, in Deep Carbon Past to Present, ed. O. B. N., I. Daniel, \& R. Dasgupta (Cambridge: Cambridge University Press), 388-414

Young, E. D., Kohl, I. D., Sherwood Lollar, B., Etiope, G., Rumble III, D., Li, S., Haghnegahdar, M., Schauble, E. A., McCain, K. A., Foustoukos, D. I., Sutcliffe, C. N., Warr, O., Ballentine, C. J., Onstott, T. C., Hosgormez, H., Neubeck, A., Marques, J. M., PerezRodriquez, I., Rowe, A. R., LaRowe, D. E., Magnabosco, C., Yeung, L. Y., Ash, J. L., \& Bryndzia, L. T. 2017, Geochemica et Cosmochimica Acta, 203, 235

Young, E. D., Rumble, D., Freedman, P., \& Mills, M. 2016, International Journal of Mass Spectrometry, 401, 1

Yung, Y. L., Chen, P., Nealson, K., Atreya, S., Beckett, P., Blank, J. G., Ehlmann, B., Eiler, J., Etiope, G., Ferry, J. G., Forget, F., Gao, P., Hu, R., Kleinböhl, A., Klusman, R., Lefèvre, F., Miller, C., Mischna, M., Mumma, M., Newman, S., Oehler, D., Okumura, M., Oremland, R., Orphan, V., Popa, R., Russell, M., Shen, L., Sherwood Lollar, B., Staehle, R., Stamenković, V., Stolper, D., Templeton, A., Vandaele, A. C., Viscardy, S., Webster, C. R., Wennberg, P. O., Wong, M. L., \& Worden, J. 2018, Astrobiology, 18, 1221 